\title{
Application of silvicultural system, yield regulation and thinning practices in natural forests: case study from western Terai
}

\begin{abstract}
V. R. Subedi ${ }^{1 *}$, K. D. Bhatta ${ }^{2}$, I. P. Poudel ${ }^{3}$ and P. Bhattarai ${ }^{4}$
Harvesting of mature forest crop, regenerating the harvested area and tending of young crop are major silvicultural operations in forest management. Silvicultural system provides a framework for carrying out these silvicultural operations in a systematic manner. Yield is the annual amount of produce that can be realized sustainably. Similarly, thinning is the principal tending operation carried out in immature crop, is more often complicated in natural forest. This paper attempts to review silvicultural system applied in Terai region of Nepal under scientific forest management in order to regulate yield and to suggest new methods of thinning in natural forests. The study was conducted in Buddha Shanti Collaborative Forest in Nawalparasi district, western Terai Nepal. Data related to implementation status of CFM Plan were collected through field observation. Harvesting data were collected during harvesting operation. The collected harvesting data were analyzed for yield regulation. Irregular shelter-wood system was applied in Buddha Shanti CFM. The applied method of yield regulation is combination of area and stem control. Area control is applied for regeneration period. Annual harvest is controlled by number of stems. Tree harvesting area is fixed for ten years and annual harvesting amount is fixed by number of tree. In this method annual numbers of trees for harvesting are fixed. Total enumeration method was applied for thinning to find out the most frequent size of pole in selected sub compartment. During the enumeration process; distance between the every stem and fore bearing was also recorded with the help of laser distance meter and compass. A stem map was prepared with the help of Arc-GIS and the grid distance was fixed based on the most frequent size of stem. Then, one stem from each grid was selected for retaining after harvesting and remaining stems were cut down. This method provides appropriate guideline for implementing it objectively by reducing subjective judgment and provide more systematic method for thinning. The field practices of application of silvicultural system and yield regulation were found in accordance to the scientific forest management Procedures 2014 in Buddha Shanti CFM. The method for thinning applied in the CFM was found applicable to other similar type of forests.
\end{abstract}

Key words: Silvicultural system, stem mapping, thinning, yield regulation

\begin{abstract}
A silvicultural system is a procedure or treatment that includes all of the management functions which meet the landowner's present and long-range objectives. It sets the stage for the next regeneration cut. Silviculture prescriptions include harvesting to promote growth, quality, or regeneration of a timber stand(Michigan, 2008). Silvicultural system provides framework for carrying out different silvicultural operations.
\end{abstract}

Scientific forest management is "the systematic application of forestry science for the management of forests. It is based on the correct assessment of attributes of forest crop to maximize and sustain benefits (including indirect benefits such as environmental and ecosystem services) accruing from the forest. Scientific forest management essentially follows silvicultural system" (MFSC, 2014). Scientific forest

\footnotetext{
${ }^{1}$ District Forest Officer, Nawalparasi * E-mail: vijayasubedi@yahoo.com

${ }^{2}$ District Forest Officer, Kapilbastu

${ }^{3}$ Under Secretary, Department of Forests

${ }^{4}$ Assistant Forest Officer, District Forest Office, Nawalparasi

92
} 
management is in implementation for last seven years (since FY 2011/2012) in different districts of Nepal. The fifth National District Forest Officers' (DFOs) workshop declared the need of application and continuation of silvicultural system based management and scientific forest management in all forest management regimes (DoF, 2014). Scientific forest management emphasizes; application of silviculture system, measurement based decisions, application of principles of forestry, analysis of economic efficiency and promotion of good governance. It's main objective is to promote sustainable management of forest. Silvicultural system is a planned program of silvicultural treatments designed to achieve specific stand structure and characteristics to meet site objectives during the whole life of a stand. This program of treatments integrates specific harvesting, regeneration, and stand tending methods to achieve a predictable yield of benefits from the stand over time (British Colombia, 2003).The current level of forest productivity is much lower than the potential in Nepal. The cost of not having scientific forest management and silvicultural operations is estimated NRs 100 billion per year (MFSC, 2014). Revised Forest Policy 2000 has prioritized silvicultural system based management of block forests (forests greater than 500 ha in area) in Terai and Inner Terai of Nepal. Similarly it has indicated the need of collaborative management of Terai forests to include distance users in forest management (MFSC, 2000). There is no specific guideline to conduct thinning in natural forest and it is a matter of ocular judgment which depends on person and experience, thus, influence the crop stock and productivity. Until today, thirty forest patches are under collaborative forest management based on silvicultural system. The research site, Buddha Shanti CFM is one among them (DoF, 2017). Therefore, this study reviews the silvicultural system applied in study site, under scientific forest management to regulate yield and thinning.

\section{Materials and methods}

Buddha Shanti Collaborative Forest is situated in Nawalparasi district of Western Development Region of Nepal. Geographically, it extends from $27^{\circ} 30^{\prime} 00^{\prime \prime} \mathrm{N}$ to $27^{\circ} 40^{\prime} 00^{\prime \prime} \mathrm{N}$ latitude and from $83^{\circ} 35^{\prime} 00^{\prime \prime} \mathrm{E}$ to $83^{\circ} 40^{\prime} 00^{\prime}$ ' E longitude. The site does have tropical climate with elevation from 190 meters to 225 meters above sea level (DFO,
2010). The location map, compartment, sub compartment of the study area (Fig. 1.)

Total area of forest is 1781.32 ha, out of which, 1204.10 ha is core managed area and 577.22 ha is considered as fringe area. Core managed area is divided into three compartments and $24 \mathrm{sub}$ compartments. The major species are Sal (Shorea robusta), Saj (Terminalia tomentosa) and Karma (Adina cordifolia) (DFO, 2014). Core area is an area allocated for management and further divided into compartment and sub-compartments. Fringe area is area surrounding the core area, which is not divided into compartments and subcompartments, and management is limited to protection and fallen tree collection. The purpose of fringe area is to provide protection to core area and address social issues such as encroachment, surrounding community interests.

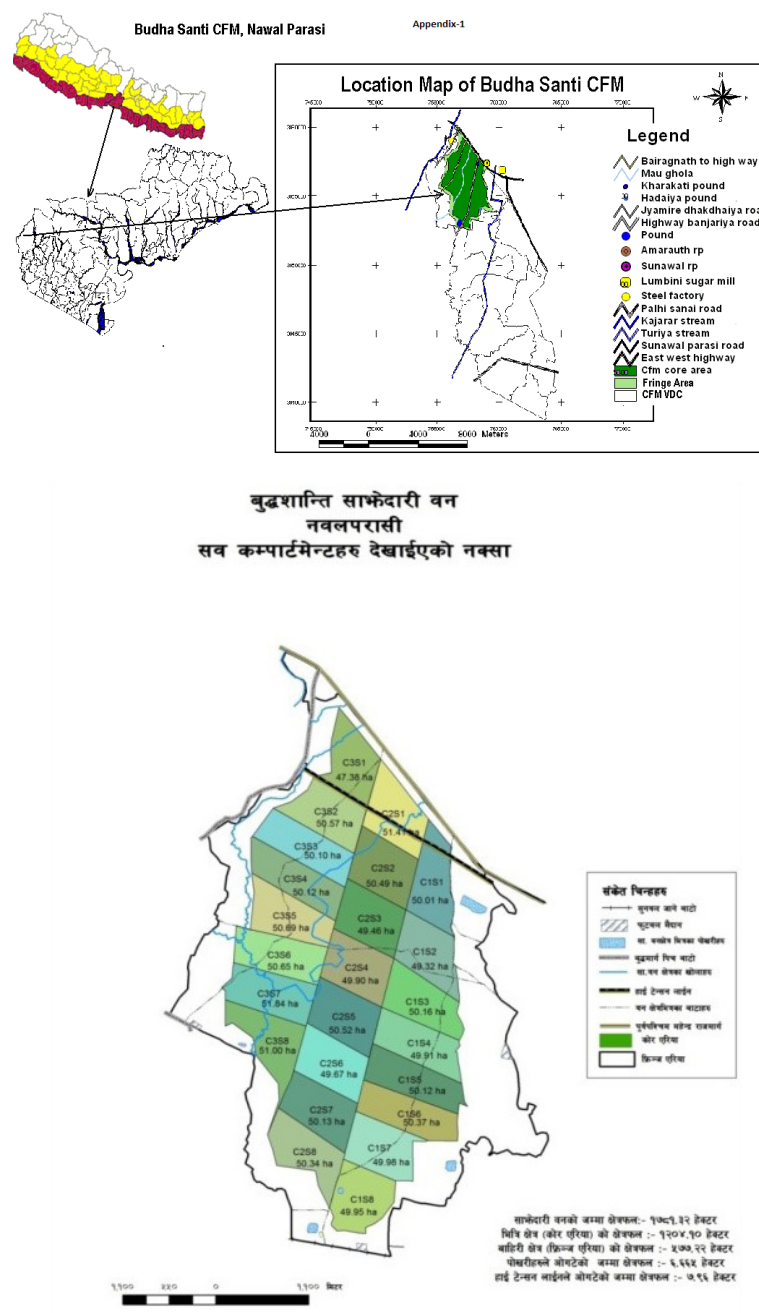

Fig. 1:Study area location with compartment and sub compartment division map 


\section{Literature Review}

Concerned policies and legislative documents of Government of Nepal, study reports, journal articles, and websites relating to Silvicultural system were reviewed. Specifically, this study reviews the approved management plan of Buddha Shanti Collaborative Forest. The plan was reviewed for the purpose of comparing with the Scientific Forest Management Procedure, 2014 and compare the actual practices in the field against the approved management plan.

\section{Field observation}

Field observation was carried out to understand field situation and proposed management activities on silvicultural system, yield regulation and thinning. During the field observation, implementation status of silvicultural system and yield regulation was observed, photographed, measured and noted during the study. Specifically, information on plan implementation status was obtained during the field observation.

\section{Data collection}

In order to design appropriate method of thinning; total enumeration of sapling and pole was conducted in related sub compartment. Global Positioning System (GPS), compass, laser distance meter and diameter tape were used to capture the position, distance and diameter data of stem.

Data were analyzed by classifying, grouping, tabulating and frequency analysis techniques. Microsoft Excel and Arc-GIS was used for data analysis and exploration.

\section{Results and discussions}

\section{Silviculture system}

Silviculture systems are based on felling intensity. The major silviculture systems are; Clear Felling, Shelter wood and Selection System.

- $\quad 100 \%$ felling intensity $=$ Clear Felling System

- $\quad 70-90 \%$ felling intensity $=$ Shelter wood System
- $\quad 10-30 \%$ felling intensity = Selection System

Each Silviculture System has its specific framework for harvesting of mature crop, regenerating and tending of young crop. In Buddha Shanti CFM, Shelter wood (irregular) system has been applied for its management and rotation period is 80 years. Recommendation of this system is based on species i.e. Terai Sal (Shorea robusta) forest.

Forest area is divided into compartment and Sub-compartments for the implementation of different silviculture operation. In Buddha Shanti CFM, there are three compartments and each compartment has eight sub-compartments. Number of compartment were based on forest area (max. area $=400$ ha). Number of subcompartments (periodic blocks) was calculated based on the Rotation (R) and Regeneration Period (Rp).

- Number of sub compartment $=\mathrm{R} / \mathrm{Rp}=80 / 10$ $=8$ (of equal area)

Major Silviculture operations recommended in Buddha Shanti CFM are regeneration felling, preparatory felling, thinning and improvement felling, climber cutting in grown up stands and regeneration promotion. Regeneration felling is concentrated in one sub-compartment of each compartment where majority of over mature trees exist and regeneration is in comparatively poor condition. Preparatory felling is recommended in one sub-compartment of each compartment where majority of over mature trees are in second position, regeneration is fewer and regeneration felling is targeted after the completion of existing plan. Thinning and improvement felling is designed in four sub-compartment of each compartment where pole and sapling were in dense condition. Climber cutting in grown up stands is recommended in two sub-compartments of each compartment to increase growth and improve quality of tree. 
Table 1: The management plan of Buddha Shanti CFM has the following ten years plan of different Silviculture Operations in different sub-compartments

\begin{tabular}{ll}
\hline Year & Silviculture Operations \\
\hline 1st & - Regeneration Felling and Regeneration \\
2nd & Promotion in C1S1, C2S2 and C3S1 \\
& - Regeneration Felling and Regeneration \\
& Promotion in C1S1, C2S2 and C3S1 \\
& - Thinning and Improvement Felling in \\
& C1S8, C2S8 and C3S8 \\
3rd & -Regeneration Felling and Regeneration \\
& Promotion in C1S1, C2S2, C3S1 \\
& - Thinning and Improvement Felling in \\
& C1S7, C2S7 and C3S7 \\
4th & -Regeneration Felling and Regeneration \\
& Promotion in C1S1, C2S2, C3S1 \\
& - Climber cutting in grown up stands in \\
& C1S3, C2S3 and C3S3 \\
5th & -Regeneration Felling and Regeneration \\
& Promotion in C1S1, C2S2, C3S1 \\
& - Preparatory Felling in C1S2, C2S1 and \\
& C3S2 \\
6th & -Regeneration Felling and Regeneration \\
& Promotion in C1S1, C2S2, C3S1 \\
& - Thinning and Improvement Felling in \\
& C1S6, C2S6 and C3S6 \\
7th & -Regeneration Felling and Regeneration \\
& Promotion in C1S1, C2S2, C3S1 \\
& - Climber cutting in grown up stands in \\
8th & C1S4, C2S4 and C3S4 \\
& -Regeneration Felling and Regeneration \\
& Promotion in C1S1, C2S2, C3S1 \\
& - Thinning and Improvement Felling in \\
9th & C1S5, C2S5 and C3S5 \\
& -Regeneration Felling and Regeneration \\
10th & $\begin{array}{l}\text { Promotion in C1S1, C2S2, C3S1 } \\
\text {-Regeneration Felling and Regeneration } \\
\end{array}$ \\
\hline & Promotion in C1S1, C2S2, C3S1 \\
\hline
\end{tabular}

Field observation revealed that the above silvicultural activities were implemented according to the plan to a greater extent except slight lag in thinning activities. The plan activities are also according to the Scientific Forest Management Procedure, 2014, of the Department of Forests. It was observed that the silviculture operations and treatments are based on tree size and age; treatments are clearly assigned to each sub-compartment, silviculture operations are clear and scheduled for plan period. After the proper implementation of this plan; there will be creation of different eight age classes in every compartment, forest will be converted uneven aged and in the long- run forest will be changed into normal forest.

\section{Yield regulation}

Yield is the total amount that can be harvested per period, or the total amount that could be removed at any time (Florida Forest Stewardship, 2010). Yield is realized through carrying out Silviculture Operations as planned.

Yield regulation in Buddha Shanti CFM is based on area and number of stem per unit of area. Stem mapping has been conducted in regeneration felling sub compartment (Periodic block) to find out total number of tree, number of mother tree (seed tree) and number of felled trees in sub compartment. Stem map has been prepared, mother trees and annual harvestable trees are shown below (Fig. 2) for regeneration felling sub compartment. Sample of stem mapping, mother tree and harvestable tree are shown in following figure.

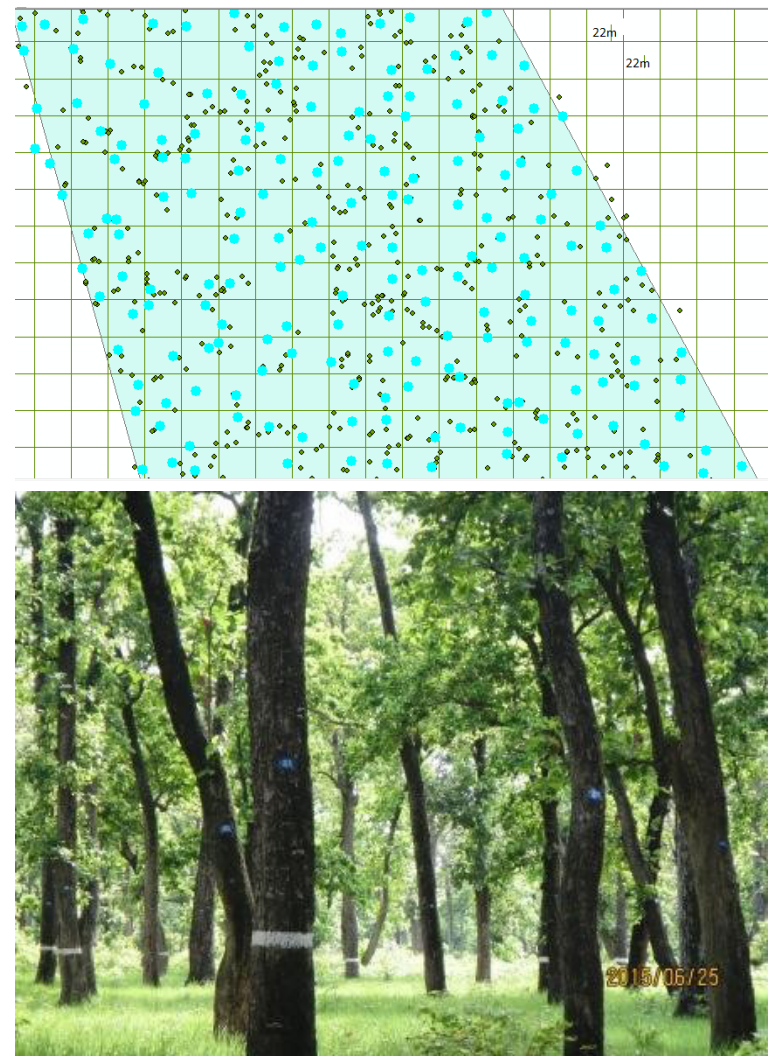

Fig. 2: Stem mapping and selection of mother tree and felled tree 
In Buddha Shanti CFM, mother trees were identified by using $22 \mathrm{~m} \mathrm{X} 22 \mathrm{~m}$ grid in stem map, one tree nearest from centre of grid was fixed as mother tree. During the tree chhapan (stamping tree) for felling; mother tree has been verified, if the mapped mother tree is found not suitable (i.e. dead, dying, diseased, deformed, over mature, etc.) in field verification then appropriate tree (i.e. middle aged tree of size $40 \mathrm{~cm}$ to $70 \mathrm{~cm}$ diameter, straight bole, good crown condition, healthy tree, species composition, etc) nearest that was replaced as mother tree. Mother tree has been separated by four inch circular ring paint in bole above four feet from the ground. Yield regulation by area and number of stem methods used in Buddha Shanti CFM (for first compartment) was as follows.

- Area of sub-compartment $(\mathrm{C} 1 \mathrm{~S} 1)=50.49$ ha

- Total number of trees in $\mathrm{C} 1 \mathrm{~S} 1=3026$

- Identified mother trees by using $22 \mathrm{~m} \mathrm{X} 22 \mathrm{~m}$ grid $=808$

- Identified trees for felling in $\mathrm{C} 1 \mathrm{~S} 1=3026$ $808=2218$

- Trees harvested annually in $\mathrm{C} 1 \mathrm{~S} 1=2218 / 10$ $=221.8$

Yied is regulated by harvesting 221 trees in C1S1 (50.49 ha) sub compartment, 204 trees in C2S2 (50.49 ha) sub compartment and 226 trees in C3S1 (47.38 ha) annually. The annual volume yield of forest was equivalent to the volume of 651 trees. Priority of harvesting is given in area where regeneration is poor and majority of trees are old.

As explained earlier; tree harvesting area is fixed for 10 years and annual harvesting amount is fixed by number of tree hence the yield regulation method is area and stem control. In this method number of mother tree and annual harvesting trees are fixed for 10 years which is technically less complicated and required less skilled human resources.. This yield regulation method is in accordance to the CFM plan and Scientific Forest Management Procedure, 2014.

\section{Thinning}

Thinning is considered as principal tending operation. The aim of thinning is to achieve appropriate stand density and enhance diameter growth. In Buddha Shanti CFM, the provision of thinning is in four sub-compartments of each compartment. The thinning is targeted for sapling, pole and young tree within the subcompartments. The sub compartment provisioned for thinning are C1S8, C1S7, C1S6, C1S5, $\mathrm{C} 2 \mathrm{~S} 8, \mathrm{C} 2 \mathrm{~S} 7, \mathrm{C} 2 \mathrm{~S} 6, \mathrm{C} 2 \mathrm{~S} 5, \mathrm{C} 3 \mathrm{~S} 8, \mathrm{C} 3 \mathrm{~S} 7, \mathrm{C} 3 \mathrm{~S} 6$ and C3S5. The retaining number of stem after thinning is explained in management plan based on the size of stem. However, proper method for such thinning operation is lacking.

If the nature of stand is uneven aged (old trees to young pole and saplings); the challenge is to apply appropriate method. In Buddha Shanti CFM, the size of stem (diameter distribution) is heterogeneous. The spacing between the stems depends upon the size of stem to be retained after thinning. Number and average size of stem need to be assessed to fix the required number of stem in sub-compartment. For this objective; the condition of pole and sapling in four sub compartments of each compartment were assessed through sampling method. This helps to maintain age class after thinning. One subcompartment is selected in second compartment with field verification for thinning. During the selection process, the denseness of stand and the targeted size of $15-20 \mathrm{~cm}$ diameter were considered. Total enumeration was done to find out the most frequent size of pole in selected subcompartment. During the enumeration process; distance between the every stem and fore bearing was also recorded with the help of laser distance meter and compass. Based on recorded data, the most frequent size of stem was identified and the required number of stems in the sub-compartment was fixed. A stem map was prepared with the help of Arc-GIS and the grid distance was fixed based on the most frequent size of stem. Then, one stem from each grid (grid size depending upon size of stand to be retained, in this case 15-20 cm; distance- $2.5 \mathrm{~m}$ ) was selected for retaining after thinning and remaining stems were cut down. The designed method is presented in table 2, which shows the desirable number of stems per hectare by age (size) for Sal forest. This table is based on the management plan prescription (in other forests namely Dumkibas-Arunkhola Block Forest plan).

This method of thinning has merits as well as some constraints. It is easy to fix the required distance, more objective, technically standard and reduces the personal error but it demands relatively more skilled human resource for enumeration and 
Table 2: The designed method for thinning

\begin{tabular}{cccccl}
\hline S.N. & $\begin{array}{c}\text { DBH Class } \\
\mathbf{( c m})\end{array}$ & $\begin{array}{c}\text { Approx. No of } \\
\text { Stems }\end{array}$ & $\begin{array}{c}\text { Approx. Age } \\
(\mathbf{y r s})\end{array}$ & $\begin{array}{c}\text { Distance } \\
(\mathbf{m})\end{array}$ & Principal Silviculture Operation \\
\hline 1 & $10-15$ & $3000-4000$ & 10 & 1.6 & Thinning (and/or Improvement Felling) \\
2 & $15-20$ & $1500-2000$ & 20 & 2.2 & Thinning (and/or Improvement Felling) \\
3 & $23-28$ & $750-1000$ & 30 & 3.2 & Thinning (and/or Improvement Felling) \\
4 & $30-35$ & $375-500$ & 40 & 4.5 & Thinning (and/or Improvement Felling) \\
5 & $35-40$ & $200-250$ & 50 & 6.3 & Thinning (and/or Improvement Felling) \\
6 & $40-45$ & $200-250$ & 60 & & Final Thinned Stand \\
7 & $45-50$ & $150-200$ & 70 & & Preparatory Felling \\
8 & $50-55$ & $15-25$ & 80 & & Regeneration Felling (Seeding Felling) \\
\hline
\end{tabular}

measurement especially for identifying stems to be retained with the help of GIS.

\section{Conclusion}

Applied silviculture system in Buddha Shanti CFM is Irregular shelter-wood system. The silviculture operation and method of yield regulation is clearly defined and it has provided clear framework for carrying out different silviculture operations (harvesting of mature crop, regeneration and tending of young crop) systematically. The applied method of yield regulation is combination of area and stem control. Area control is applied for regeneration period $(=$ plan period $=10$ years $)$. Annual harvest is controlled by number of stems. Tree harvesting area is fixed for ten years and annual harvesting amount is fixed by number of tree. This is based on area and stem for yield regulation and control. In this method, annual numbers of trees for harvesting are fixed. Thus, it is technically less complicated and easier to complete. Thinning is complicated in natural forest. However explained method provides appropriate guideline for implementing it objectively while reducing subjective judgment and providing more systematic method. Hence, it is useful for maintaining uniformity and reducing personal bias.

\section{References}

DFO, Nawalparasi, 2010. Collaborative Management Scheme of Buddha Shanti Forest. District Forest Office (DFO), Nawalparasi, Nepal.
DFO, Nawalparasi, 2014. Collaborative Management Scheme of Buddha Shanti Forest. District Forest Office. Nawalparasi, Nepal:

DoF 2014. Community Forestry Bulletin No 16, Department of Forests (DFO), Kathmandu Nepal. pp 41-46.

D0F 2017. Community Forestry Bulletin No 17, Department of Forests (DFO), Kathmandu Nepal. pp 13-21.

Florida Forest Stewardship, 2010. University of Florida. Florida, U.S.A. www.sfrc.ufl. edu/extension/florida_forestry_information/ forest management/growth_and_yield.html. Accessed on 12 December, 2017.

MFSC, 2000. Revised Forest Policy 2000. Ministry of Forests and Soil Conservation (MFSC), Kathmandu Nepal.

MFSC, 2014. Scientific Forest Management Working Procedure (2071 B.S.). Ministry of Forest and Soil Conservation (MFSC). Kathmandu, Nepal.

Michigan Forests Forever Teachers Guide, Mfd. dsisd.net/balance/MSAF/Guide/Silvsystems. htm. Accessed on 12 December 2017.

British Columbia. Ministry of Forests. Forest Practices Branch. 2003. Silvicultural Systems Handbook for British Columbia. For. Pract. Br., BC. Min. For., Victoria, BC.Canada. 